\title{
Europe-wide centre for disease control by 2005
}

The European Union will confront the threat from future epidemics through a new EU Centre for Disease Prevention and Control (ECDC) to be launched and operational in 2005.

It took just 8 months for the EU Parliament and Council of Ministers to turn the European Commission's proposal into reality. Commenting on the legislative fast-track the European $\approx$ Commission Health and Cona sumer Protection Commissioner David Byrne said lessons had been learned from SARS and ô bird flu. "Infectious diseases can $\stackrel{?}{\circ}$ pose a deadly threat — and they do not respect national borders."

§ The EU already has a system for Europe-wide epidemiological surveillance of infectious disease, but cooperation to investigate and control epidemics is ad hoc.

The ECDC, based in Stockholm, Sweden, will deploy outbreak investigation teams more quickly. The agency will also coordinate existing expertise on infectious disease.

The ECDC will play a crucial role in tackling and preventing a future influenza pandemic according to a working paper adopted by the European Commission in March. It says the plan is a "launchpad for debate on co-ordinating preparedness against influenza," and details how the EU and member states should respond to an outbreak.

The plan calls for the creation of an EU network of reference laboratories for human influenza and the creation of "outbreak assistance teams." These teams would investigate reports of outbreaks both inside and outside the EU and provide expertise to national and local health authorities during outbreaks.

The plan also describes European Medicines Evaluation Agency procedures that allow for the rapid approval of pandemic influenza vaccines and the communication strategies necessary to prevent media speculation and rumour. - Colin Meek, Wester Ross, Scotland

\section{Global Health}

\section{Alcohol rivals tobacco for health impact: WHO}

WHO warns that the global health impact of alcohol now rivals that of smoking.

A report this month documents a marked increase in the $\widehat{\infty}$ incidence of alcohol-related disó eases and deaths worldwide and suggests ways to curb the impact. Alcobol's Role in the Global Burden of Disease states that drinking 응 even small amounts of alcohol greatly increases the chance of

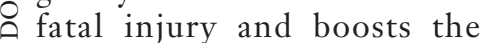

chances of developing diseases such as cancer, neuropsychological disorders and liver cirrhosis.

Jurgen Rhem, a scientist at the University of Toronto's Centre for Addiction and Mental Health and one of the study's coauthors, says the ills of alcohol have gone largely unnoticed in light of high-profile antismoking campaigns.

"In terms of perception there is one disease that is clearly as-

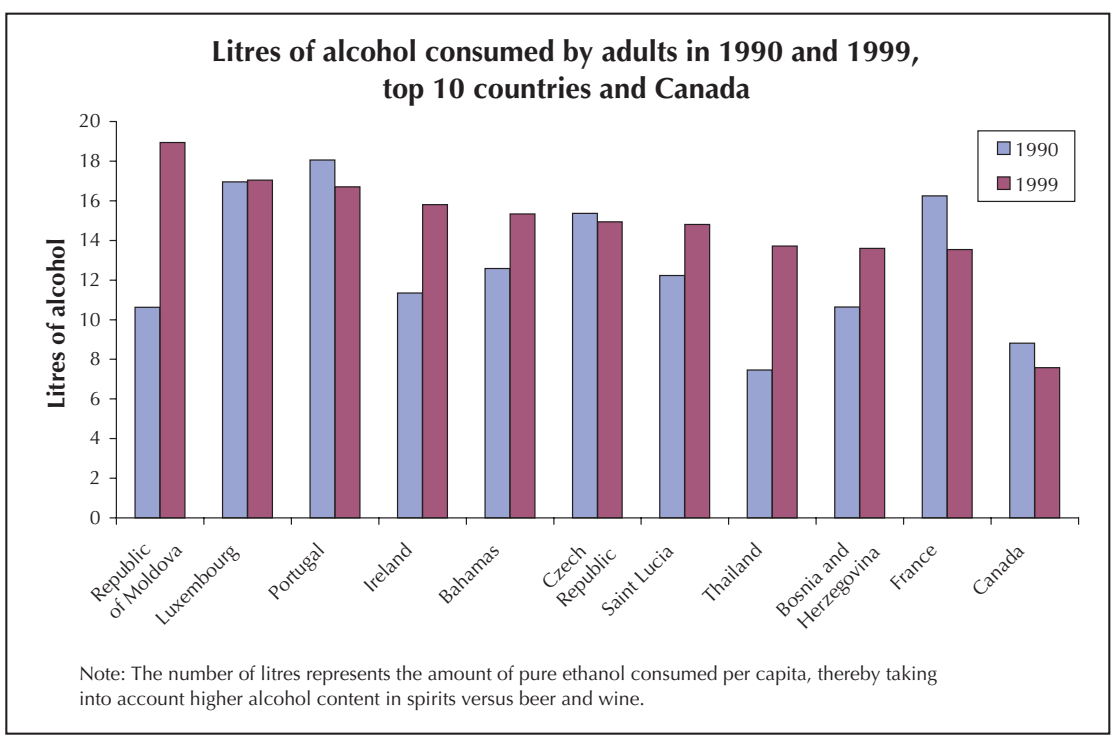

sociated with tobacco, namely lung disease," he says. Alcohol use, on the other hand, "is related to 60 different diseases, but with most of those diseases alcohol is to blame for a smaller percentage, from 5\%-50\%."

"I think that makes a difference in the public perception and that's why alcohol is much more difficult [to deal with]."

According to WHO data, alcohol consumption has increased in many of the former USSR republics as well as in developing countries, as is the case with Thailand (see Figure).

WHO's warning seems to contradict recent highly publicized research that highlighted the cardiovascular benefits of moderate wine drinking. Rhem says they factored this into the research, subtracting any health benefits from the results.

The WHO study makes several recommendations including advertising bans and increasing taxes. Recent research has shown the most effective tool in curbing alcohol consumption is a price increase. - Brad Mackay, Toronto 